\title{
Therapeutic effectiveness of bacteriophages in the rescue of mice with extended spectrum B-lactamase-producing Escherichia coli bacteremia
}

\author{
JING WANG ${ }^{1 *}$, BEI HU ${ }^{2 *}$, MINCHAO XU ${ }^{2 *}$, QUN YAN ${ }^{2}$, SHUANGYOU LIU ${ }^{2}$, XUHUI ZHU ${ }^{3}$, ZIYONG SUN $^{3}$, \\ DEDING TAO ${ }^{2}, \mathrm{LI} \mathrm{DING}^{4}$, EDDIE REED ${ }^{5}$, JIANPING GONG ${ }^{2}$, QINGDI Q. $\mathrm{LI}^{5}$ and JUNBO HU ${ }^{2}$ \\ ${ }^{1}$ Department of Immunology, Tongji Medical College; ${ }^{2}$ Molecular Medicine Center and Department of Surgery; \\ ${ }^{3}$ Department of Laboratory Medicine, Tongji Hospital, Central China University of Science and Technology, Wuhan 430030, \\ P.R. China; ${ }^{4}$ Laboratory of Clinical Infectious Diseases, National Institute of Allergy and Infectious Diseases, National \\ Institutes of Health, Bethesda, MD 20892; ${ }^{5}$ Mary Babb Randolph Cancer Center and Department of Microbiology, \\ Immunology and Cell Biology, West Virginia University Health Sciences Center, Morgantown, WV 26506, USA
}

Received October 11, 2005; Accepted November 24, 2005

\begin{abstract}
The emergence of multidrug-resistant bacteria has become a global crisis. Accumulating evidence shows that bacteriophages (phages) can rescue animals from a variety of lethal infections and be effective in treating drug-resistant infections in humans. Enterobacteriaceae, producing extended spectrum B-lactamase enzymes (ESBLs), are resistant to a broad range of $\beta$-lactamase antibiotics. One of the most common ESBL-producing gram-negative bacilli in Enterobacteriaceae is Escherichia coli. Since ESBL-producing E. coli poses a formidable challenge in the management of critically ill patients with bacterial infections, we undertook this study to explore the possible therapeutic utility of phages to control ESBL-producing E. coli infections. The phage $\varnothing 9882$ used in this study was isolated from our hospital sewage and has lytic activity against a broad range of clinical isolates of ESBL-producing E. coli. ESBL-producing E. coli strains $(n=30)$ were isolated in the clinic, and one of them was used to induce bacteremia in a murine model. Bacteremia was established by intraperitoneal (i.p.) injection of $3 \times 10^{7} \mathrm{CFU} / \mathrm{ml}$, the minimum lethal dose (MLD) of bacterium in this animal
\end{abstract}

Correspondence to: Dr Junbo Hu or Dr Jianping Gong, Department of Surgery, Tongji Hospital, Wuhan 430030, P.R. China E-mail: jbhu@tjh.tjmu.edu.cn

Dr Qingdi Q. Li, 216 Watkins Pond Boulevard, Rockville, MD 20850-5622, USA

E-mail: qli@hsc.wvu.edu

${ }^{*}$ Contributed equally

Key words: phage therapy, animal model, mouse, Escherichia coli, bacteremia, antibiotic resistance, extended spectrum B-lactamase enzymes model. Mice infected with the MLD of this strain alone died within $14 \mathrm{~h}$, whereas a single i.p. inoculation of $\varnothing 9882$ (MOI $\geq 10^{-4}$ ) given $40 \mathrm{~min}$ after the bacterial challenge led to $100 \%$ survival at $24-168 \mathrm{~h}$, compared to $0 \%$ survival of salinetreated controls. Protection was obtained even when administration of the phage was delayed up to $60 \mathrm{~min}$ after the bacterial infection and the survival rate of infected animals was $60 \%$ at $168 \mathrm{~h}$. Furthermore, it was shown that the therapeutic efficacy of $\varnothing 9882$ in lethal systemic infection in our model is due to the functional capability of the phage and not the nonspecific immune effects. Our data both in vitro and in vivo revealed that: i) the protection of mice from death occurred only in animals infected with selected bacterial strains and the virulent phage specific to them; ii) when the phages were heat-inactivated, survival of the infected mice was strikingly decreased to 0 ; and iii) the level of antibody against the phage was not substantially elevated when the bacteremic animals were protected by the phage. The present findings indicate that phages can effectively rescue our mouse model from bacteremia and death, and thus provide the rationale and framework to evaluate the therapeutical efficacy of lytic phages against fatal ESBL-producing E. coli infections in humans.

\section{Introduction}

In 1983, Knothe and colleagues reported the first isolation of Klebsiella and Serratia strains that had transferable plasmids encoding mutated enzymes that made the bacteria resistant to cefotaxime and structurally related $\beta$-lactams (1). The major mechanism for the spread of antibiotic resistance among Enterobacteria and other bacterial species is through the transfer of resistant plasmids, which occurs between bacterial strains by the process of conjugation (2). The ability of conjugation to mediate resistant plasmid transfer among different bacterial species is of central clinical importance. Extended spectrum B-lactamase enzymes (ESBLs) are believed to have mutated from a variety of plasmid-mediated 
penicillinases and can inactivate third-generation cephalosporins (ceftazidime, cefotaxime, and ceftriaxone), as well as monobactams such as aztreonam $(1,3)$. Such enzyme production often coexists with resistance to aminoglycosides, co-trimoxazole, tetracyclines and quinolones. Due to the carriage on plasmids and the promiscuous exchange of such material between bacteria, these resistance genes, such as TEM-1, TEM-2 and SHV-1, have spread widely and are also subject to mutation $(2,4-7)$.

Escherichia coli is one of the most common ESBLproducing bacteria worldwide with a different degree of drug resistance in each country (8-11). The prevalence of ESBL-producing E. coli and other ESBL-producing Enterobacteriaceae is a dilemma for clinicians because multiple drug resistance is present in most of the clinical isolates of these organisms $(12,13)$. Antibiotic resistance of E. coli contributes significantly to the problem of nosocomial infections, including urinary tract infections, respiratory tract infections and bacteremia, particularly in elderly or debilitated patients. Infections caused by ESBL-producing bacteria are difficult to detect by current susceptibility tests, and usually lead to high rates of morbidity and mortality in many areas of China $(3,9,10)$. The options for antibiotic therapy are limited in clinical practice. Therefore, the development of alternative antibacterial approaches are necessary for the treatment of a broad array of antibiotic-resistant infectious diseases.

Phages (bacteriophages) are viruses that are harmless to humans but kill bacteria, and phage therapy is a method of harnessing phages as bioagents for the treatment of bacterial infectious diseases. Phage therapy was originally introduced $\sim 80$ years ago by Felix d'Herelle, one of the discoverers of phages, and showed promise but also aroused controversy (14). Early applications of antibacterial phage therapy (1920s to 1940 s) were impeded by a number of factors, including: i) a paucity of understanding of the heterogeneity and ecology of the phages involved; ii) failure to select phages of high virulence against the target bacteria before using them in patients; iii) the use of single phages in infections by mixing several different bacteria; iv) emergence of resistant bacterial strains that occurred via a resistant mutation or lysogenization; v) failure to appropriately characterize or titrate phage preparations, in which some were inactive; vi) failure to neutralize gastric $\mathrm{pH}$ before oral phage administration; (vii) inactivation of phages by both specific and nonspecific factors in vivo; viii) liberation of endotoxins as a consequence of widespread lysis of bacteria within the body; and ix) lack of identification of availability or reliability of phage therapy. In addition, most early research into the therapeutic use of phages was poorly organized or uncontrolled, and the basic understanding of phage biology was immature (15). These factors in combination produced a negative outcome for phage therapy. Phage therapy was later abandoned in Western countries because the mass production of several effective antibiotics was clinically applied in the 1940s (16-19). However, extensive clinical research and implementation of phage therapy continued in Eastern Europe over the last 50 years (16-21). Although much work was done and some encouraging results were obtained, there was no confirmation of the validity of phage therapy in the clinic. In the past decade, there has been a revival in phage remedy because of the problem of antibiotic resistance (14,24-27). With the emergence of antibiotic-resistant bacteria such as ESBLproducing E. coli, VRE (vancomycin-resistant Enterococcus), and MRSA (methicillin-resistant Staphylococcus aureus), there is a need to explore the potential therapeutic applications of phages. We focused our efforts on ESBL-producing E. coli because it is a clinically important multidrug-resistant pathogen and the information regarding phage therapy for ESBLproducing $E$. coli-induced infections is scant. In this study, we report that phages are able to infect and kill the majority of clinical isolates of ESBL-producing E. coli in vitro. Our study also showed remarkable efficacy in phage therapy when treating mice with pernicious ESBL-producing E. coli infections without adverse effects, thereby suggesting a potential clinical application of phages to control ESBLproducing $E$. coli-induced infectious diseases in humans.

\section{Materials and methods}

Culture media. LB medium and SM buffer were prepared according to Sambrook et al (28). TSBM was TSB medium supplemented with $20 \mathrm{mM} \mathrm{MgCl}_{2}$, and PEG/NaCl was $20 \%$ PEG-8000 (w/v) supplemented with $2.5 \mathrm{M} \mathrm{NaCl}$. LB-based solid medium containing $1.5 \%$ agar and $0.7 \%$ agarose was used for the lower and upper layers, respectively. DNAse I, RNAse $\mathrm{A}$, and proteinase $\mathrm{K}$ were purchased from Becbo, Sigma, and Amresco, respectively.

Bacterial strains. The bacterial strains used in our study included 30 ESBL-producing Escherichia coli strains. All samples of ESBL-producing E. coli strains were derived from clinical specimens obtained from patients at the Tongji Hospital. In the present study, ESBL-producing E. coli 9853 served as the experimental target of our phage $\varnothing 9882$ (with a broad host range), unless otherwise stated, as ESBL-producing E. coli 9853 was sensitive to most of the isolated phages, including $\varnothing 9882$ (see below). Three other ESBL-producing $E$. coli strains were established for the animal experiments. Bacterial growth was monitored by measuring turbidity using a UV-2000 spectrophotometer. A $0.5 \mathrm{OD}_{600}$ value was assumed to be equivalent to $2 \times 10^{8} \mathrm{E}$. coli cells $/ \mathrm{ml}$. This conversion formula was based on a previously standardized correlation between turbidity and bacterial cell numbers counted directly by quantitative plating.

Isolation and purification of phage strains. The 30 ESBLproducing E. coli strains mentioned above were used as hosts to isolate specific phages from raw sewage obtained from the Sewage Treatment Center of Tongji Hospital. The isolations, performed similarly but individually for each phage strain according to Biswas et al, were accomplished by adding salt ( $58 \mathrm{~g}$ of $\mathrm{NaCl}$ ) to 1 liter of sewage, followed by centrifugation at $10,000 \mathrm{x} \mathrm{g}$ for $10 \mathrm{~min}$ (29). The supernatant was decanted into a separate container and mixed with polyethylene glycol (PEG; molecular weight, 8,000) to provide a final PEG concentration of $10 \%(\mathrm{w} / \mathrm{v})$. The PEG-containing supernatant was precipitated overnight at $4^{\circ} \mathrm{C}$ and centrifuged at $12,000 \mathrm{x} \mathrm{g}$ for $20 \mathrm{~min}$. The resulting precipitate was dissolved in $5 \mathrm{ml}$ of phage dilution buffer (SM) and extracted once with an equal volume of chloroform. An aliquot $(300 \mu 1)$ of this processed 
sewage was mixed with $200 \mu 1$ of an overnight culture of ESBL-producing E. coli strains, incubated at $37^{\circ} \mathrm{C}$ for $20 \mathrm{~min}$, mixed with $3 \mathrm{ml}$ of molten top agar $(0.7 \%$ agarose $)$ at $50^{\circ} \mathrm{C}$, and poured onto LB agar plates (1.5\% agar; see above). Plates were incubated overnight at $37^{\circ} \mathrm{C}$. Phage plaques were harvested from the plate, and single plaques were purified 3 times on host strains using standard procedures described by Sambrook et al (28).

Large-scale amplification and purification of phage particles. Phage $\varnothing 9882$ was purified according to the procedure described by Sambrook et al. ESBL-producing E. coli 9882 host cells suspended at $2 \times 10^{8}$ cells $/ \mathrm{ml}$ in $20 \mathrm{ml} \mathrm{LB}$ medium were exposed to a crude preparation of $\varnothing 9882$ at an MOI of 0.01 and vigorously shaken for $4-5 \mathrm{~h}$ at $37^{\circ} \mathrm{C}$, resulting in the complete lysis of bacteria (28). After 10 min treatment with $1 \%$ chloroform at $37^{\circ} \mathrm{C}$, and treatment with $1 \mu \mathrm{g} / \mathrm{ml}$ DNase I and $1 \mu \mathrm{g} / \mathrm{ml} \mathrm{RNase} \mathrm{A}$ for $30 \mathrm{~min}$ at $37^{\circ} \mathrm{C}$, the culture fluid was centrifuged at $12,000 \times \mathrm{g}$ for $10 \mathrm{~min}$ at $4^{\circ} \mathrm{C}$ to remove cell debris. $\mathrm{PEG} / \mathrm{NaCl}$ was added to the supernatant to a final concentration of $1 / 6(\mathrm{v} / \mathrm{v})$ and kept overnight at $4^{\circ} \mathrm{C}$. The resultant precipitate containing the phage particles was collected by centrifugation at $10,000 \mathrm{x} \mathrm{g}$ for $20 \mathrm{~min}$ at $4^{\circ} \mathrm{C}$, resuspended in $500 \mu \mathrm{l} \mathrm{SM}$ buffer, and the phage suspension was placed on top of a discontinuous $\mathrm{CsCl}$ gradient $(\mathrm{Q}=1.3$, 1.5 , and 1.7), then centrifuged at $25,000 \mathrm{x}$ g for $2.5 \mathrm{~h}$ at $4^{\circ} \mathrm{C}$ (Beckman SW41 rotor). The phage band was collected and dialyzed against $10 \mathrm{mM}$ saline that contained $50 \mathrm{mM}$ Tris-Cl (pH 8.0) and $10 \mathrm{mM} \mathrm{MgCl}_{2}$ for $2 \mathrm{~h}$ at $4^{\circ} \mathrm{C}$. CsCl-gradient separation and dialysis $(1 \mathrm{~h})$ were repeated. The purified phage suspension was divided into aliquots and stored at $4^{\circ} \mathrm{C}$ until used. The samples were appropriately diluted with LB just before use for infections. The titers (PFU/ml) of purified samples were determined by inoculating them into $E$. coli 9882 strain.

Screening phage with broad host range. To select the phage with a broad host range in vitro, the 30 ESBL-producing $E$. coli strains were used to make lawns on a solid culture. The back of the plate was divided into 16-20 panes, and all panes were marked with the name of corresponding phages. Phages $(1 \mu \mathrm{l})$ were dropped onto the plates and cultured at $37^{\circ} \mathrm{C}$ for $12-16 \mathrm{~h}$.

Biological characterization of phage $\emptyset 9882$. The adsorption rate, latent period, and burst size of $\varnothing 9882$ were determined according to the method of Adams (30). All incubations were carried out in $\mathrm{LB}$ medium at $37^{\circ} \mathrm{C}$. In brief, to examine the adsorption rate, $\varnothing 9882\left(5 \times 10^{9} \mathrm{PFU} / \mathrm{ml}\right)$ was mixed with ESBL-producing E. coli 9882 cells $\left(5 \times 10^{7} \mathrm{CFU} / \mathrm{ml}\right)$, and the number of free infectious phage virions was measured in the phage-cell mixture diluted 1,000 times. To determine the latent period and burst size, E. coli 9882 cells $\left(5 \times 10^{6} \mathrm{CFU} / \mathrm{ml}\right)$ were exposed to $\varnothing 9882\left(5 \times 10^{7} \mathrm{PFU}\right)$ for $5 \mathrm{~min}$, washed thoroughly with cold TSBM medium to remove unbound phages, and resuspended in fresh medium. An aliquot of the cell suspension was harvested regularly during incubation at $37^{\circ} \mathrm{C}$ to be titrated for newly produced phages, both released and cell-associated phages, on a lawn of ESBL-producing E. coli 9882 .
Animal experiments. Phage $\varnothing 9882$, screened as having the broadest host range, was used to rescue bacteremic mice. ESBL-producing E. coli 9853 , one of our 30 ESBL-producing E. coli strains, was used to infect mice as it was sensitive to most isolated phages, including $\varnothing 9882$. Varying numbers of bacterial cells suspended in $0.5 \mathrm{ml}$ saline were injected into the peritoneal cavities of mice through one side of the abdomen, and the purified phage suspensions in $0.5 \mathrm{ml} \mathrm{LB}$ medium were injected on the other side. As controls, equal volumes of saline or LB alone were injected intraperitoneally on all test occasions. The test animals were observed for 7 to 30 days.

Establishing the MLD in the mouse model. The experimental animals (6-8 weeks old; body weight $20 \pm 0.5 \mathrm{~g}$ ), BALB/c female mice ( 5 mice in each group), were used for infection experiments. Preparation of the infecting bacteria was as follows. ESBL-producing E. coli 9853 were grown in $100 \mathrm{ml}$ LB medium at $37^{\circ} \mathrm{C}$ and centrifuged at $8,000 \mathrm{x}$ g for $5 \mathrm{~min}$ at an early stationary phase $\left(0.5 \mathrm{OD}_{600}\right.$ value $)$. The cell pellet was washed with $100 \mathrm{ml}$ saline, centrifuged again under the same conditions, and resuspended in $5 \mathrm{ml}$ saline. After the appropriate dilution, turbidity was measured to determine bacterial cell numbers, as described above. To determine the minimum lethal dose (MLD), serial dilutions of E. coli 9853 were injected intraperitoneally (i.p.) into mice in $500 \mu 1$ aliquots. The animals were observed for 7 days.

Protective effects of phage administration against ESBLproducing E. coli in mice. The effect of dosage on the ability of the phage to rescue mice from ESBL-producing $E$. coli bacteremia was determined. In the dose-ranging study, 11 groups of mice were challenged by i.p. injection of the MLD of ESBL-producing E. coli 9853 . Each of these groups was treated with a single i.p. injection of phage $\varnothing 9882$, administered immediately after the bacterial challenge at MOIs (multiple of infection) of $0,10^{-7}, 10^{-6}, 10^{-5}, 10^{-4}, 10^{-3}, 10^{-2}, 10^{-1}, 1,10,100$, and 200 .

Effect of delay in treatment on the ability of the phage preparation to rescue bacteremic mice. In the experiment of delayed treatment, we studied the effect on outcome for various periods. The treatment (a single injection of phage $\varnothing 9882$ at the highest dose) was initiated at 0, 20, 40, 60, 180, and $360 \mathrm{~min}$ after the bacterial challenge with the MLD of E. coli 9853 . The health of these animals was monitored for 30 days.

Effects of heat-inactivated phage. An experiment was performed to determine whether phage rescue of mice with ESBL-producing E. coli bacteremia requires a phage that can grow on the bacterial host or might be associated with a nonspecific immune activation response. A sample of phage $\varnothing 9882$ with a titer of $6 \times 10^{9} \mathrm{PFU} / \mathrm{ml}$ was heat inactivated by incubation at $100^{\circ} \mathrm{C}$. Phages that had been heated for a total of $20 \mathrm{~min}$, at which time no viable phage was detectable, were used to determine whether the phage rescue of mice with ESBL-producing $E$. coli bacteremia requires functional phage or might be associated with a nonspecific immune activation response. The mice in this study were divided into three groups of 5 mice each. All mice were challenged by 


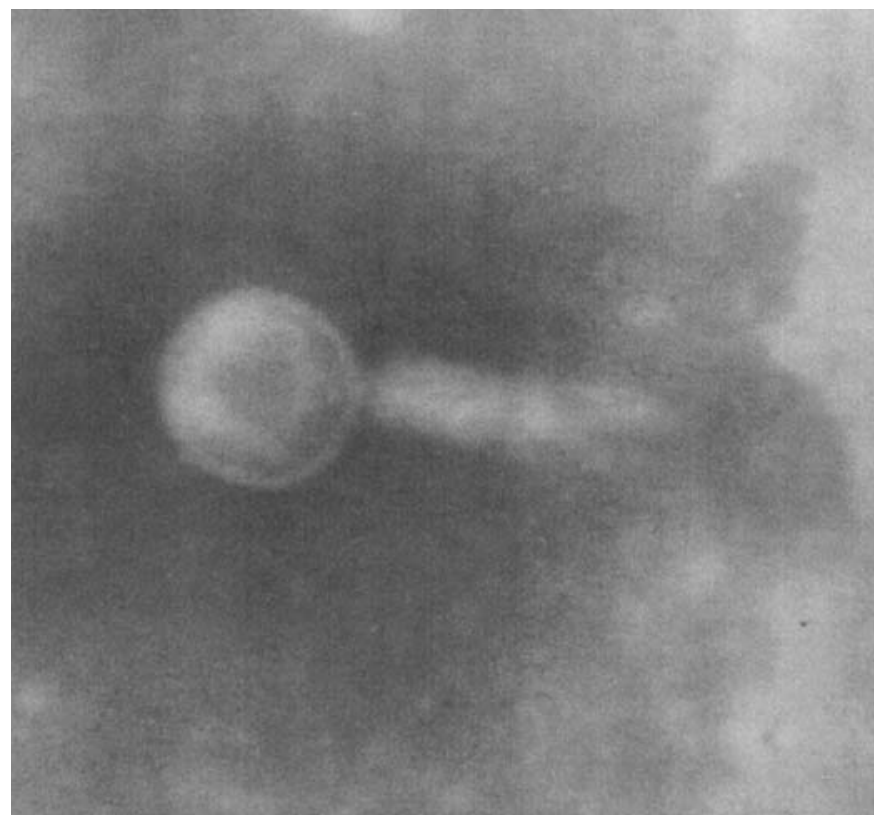

Figure 1. Electron micrograph of phage $\varnothing 9882$ (bar, $100 \mathrm{~nm}$ ). The ultrastructure under electron microscopy demonstrated that phage $\varnothing 9882$ possesses a round-shaped head of $70 \mathrm{~nm}$ in diameter and a noncontractile tail of $100 \mathrm{~nm}$ in length, with a knob-like structure at its distal end.

i.p. injection of the MLD of ESBL-producing E. coli 9853. The first group was treated with a single i.p. injection of 6x10 $10^{9} \mathrm{PFU} / \mathrm{ml}$ of phage $\varnothing 9882$ immediately after the bacterial challenge. The second group was treated with an i.p. injection of $6 \times 10^{9} \mathrm{PFU} / \mathrm{ml}$ heat-inactivated phage $\varnothing 9882$ particles immediately after the bacterial challenge. The third group, used as a control, received a single i.p. injection of LB medium instead of phage, administered immediately after the bacterial challenge.

Titers of phage $\varnothing 9882$ and E. coli 9853 in the bloodstream. Approximately $0.5 \mathrm{ml}$ of blood was taken by puncturing the orbital plexus of test mice with a capillary tube and mixed immediately with $50 \mu \mathrm{l}$ heparin $(1,000 \mathrm{U} / \mathrm{ml})$. After heparinization, the blood was diluted with saline, colonyforming units of ESBL-producing E. coli 9853 were measured on LB plates, and plaque-forming units of phage $\varnothing 9882$ were measured by using ESBL-producing E. coli 9882 as the host on LB plates. Blood samples were also collected from untreated mice to ensure that mice used in the experiments were free of naturally or accidentally contaminated phages or bacteria.

Measuring the immune response to the phage. At various time points following a single i.p. injection of phage $\varnothing 9882$ $\left(10^{9} \mathrm{PFU} / \mathrm{ml}\right)$, mouse serum was prepared, and indirect enzymelinked immunosorbent assays (ELISAs) were performed. For these assays, 2-fold serial dilutions of serum were prepared in 96-well polystyrene microtiter plates precoated with $10^{9} \mathrm{PFU} / \mathrm{ml}$ of phage $\varnothing 9882$. Immunoglobulins were detected with goat anti-mouse IgG-specific antibodies conjugated to peroxidase and tetramethylbenzadine (TMB) peroxidase substrate.

Electron microscopy. Phage preparations purified by cesium chloride density centrifugation were deposited on 400 mesh

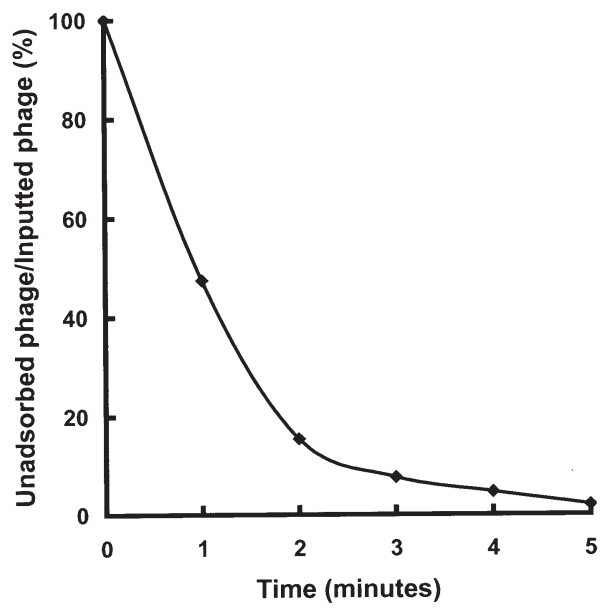

Figure 2. The adsorption rate of phage $\varnothing 9882$. Phages were mixed with excess E. coli 9882 cells, and the nonadsorbed infectious phages were serially counted. Data are percentages of nonadsorbed $\varnothing 9882$ relative to the initial input dose of phages.

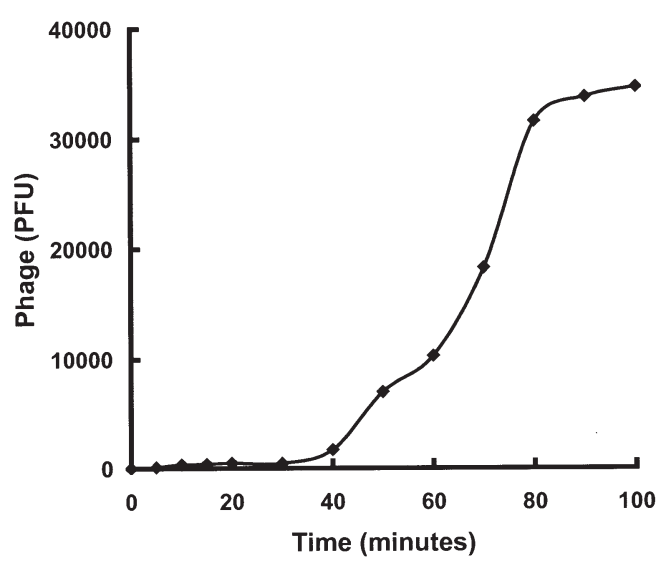

Figure 3. The one-step curve of phage $\varnothing 9882$. After a 5-min adsorption of $\varnothing 9882$ to a sufficient number of $E$. coli 9882 cells, the $\varnothing 9882$-exposed bacterial cells were thoroughly washed with tryptic soy broth medium supplemented with $20 \mathrm{mM} \mathrm{MgCl}_{2}$ at $4^{\circ} \mathrm{C}$ to remove free phages and then resuspended in fresh medium. Newly synthesized phage virions, including both released and cell-associated virions, were then measured at regular intervals during incubation using harvested culture samples.

copper grids, and stained negatively with $2 \%$ uranyl acetate ( $\mathrm{pH} 4.0)$. Grids were air-dried, and electron micrographs were taken with a transmission electron microscope (Hitachi JEM2100C; Hitachi).

\section{Results}

Isolation and screening of E. coli-specific phages with therapeutic potential. A total of 30 phage strains were isolated from the Tongji Hospital sewage, and cultures of 30 ESBLproducing $E$. coli were subjected to the spot test. Of the phage strains isolated in these experiments, phage $\varnothing 9882$ was found to form plaques on $36.67 \%$ of the ESBL-producing E. coli clinical isolates. Phage $\varnothing 9882$, screened as having a broad host range, caused bacteriolysis of 11 ESBL-producing E. coli strains, 1068, 9716, 9719, 9539, 9853, 9854, 9860, 9882, 9730, 9739, and 9914 . 


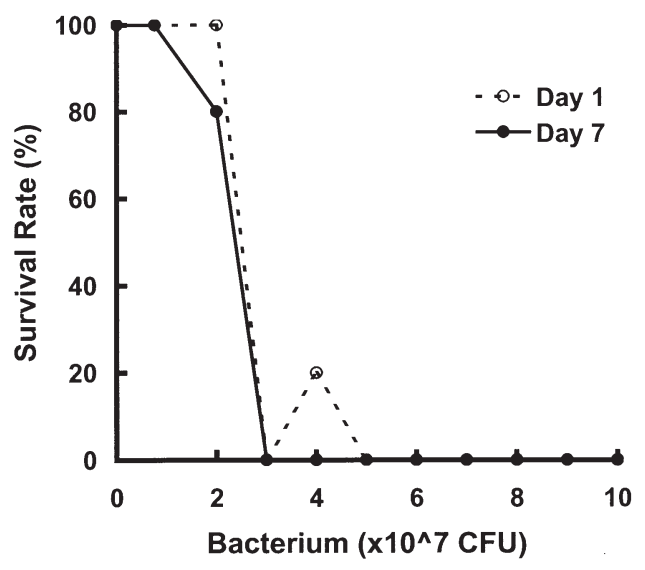

Figure 4. Determination of the lethal challenge dose of ESBL-producing E. coli 9853 to mice. Serially diluted suspensions of ESBL-producing E. coli 9853 cells were injected intraperitoneally into mice, and mouse fatalities were observed. White and black circles represent the survival rates at 1 and 7 days after injection, respectively. In the control experiment, denoted ' 0 ' on the horizontal axis, only $0.5 \mathrm{ml}$ of saline was injected.

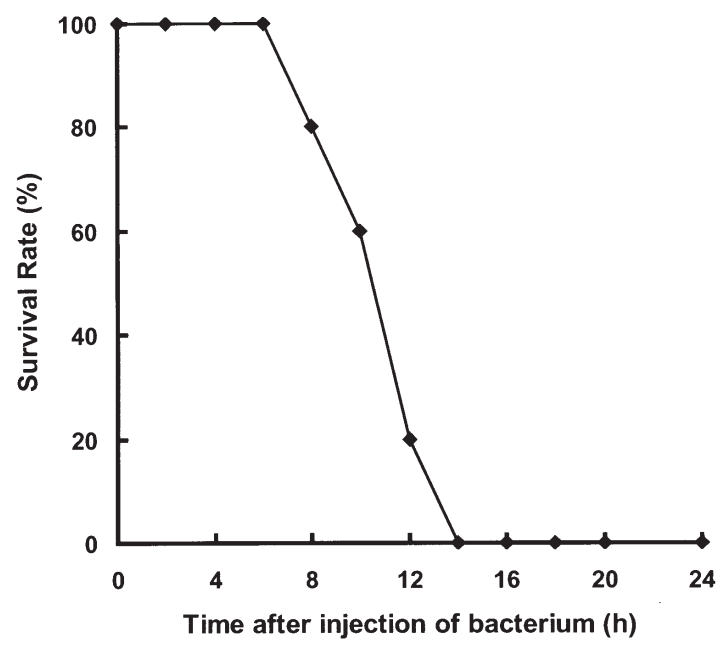

Figure 5. A precise time-chase analysis of E. coli-induced killing of mice. Five mice were each inoculated with a fixed number of ESBL-producing E. coli 9853 cells $\left(3 \times 10^{7}\right)$, and the resulting bacteremia was fatal within $14 \mathrm{~h}$.

Morphological, biological, and genetic characterizations of phage $\emptyset 9882$. Phage size measurements were performed directly on micrographs at a x70,000 magnification. As shown in Fig. 1, the ultrastructure under electron microscopy demonstrated that phage $\varnothing 9882$ possesses a round-shaped head of $70 \mathrm{~nm}$ in diameter and a noncontractile tail of $100 \mathrm{~nm}$ in length, with a knob-like structure at its distal end. Restriction-enzyme (Ecor V) analysis revealed that a $\varnothing 9882$ genome with an expected size of $30 \mathrm{~kb}$. Biological studies clarified other features of $\varnothing 9882$ (Figs. 2 and 3), such as: i) a rapid adsorption rate (when sensitive bacterial hosts were present in sufficient numbers, $98 \%$ of $\varnothing 9882$ particles bound to them within $5 \mathrm{~min}$ ); ii) a short latent period (30-40 $\mathrm{min})$; and iii) a relatively large burst size $(\sim 112)$.

Based on the evidence cited above, $\varnothing 9882$ was considered to be a suitable therapeutic phage candidate for the treatment of human ESBL-producing $E$. coli infections. Therefore, the following experiments were undertaken using $\varnothing 9882$ in an animal model.

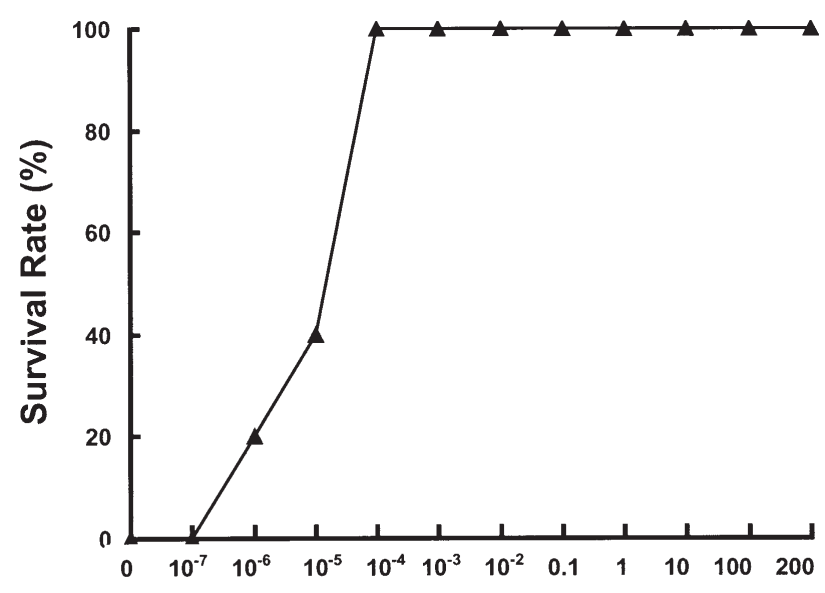

\section{Multiple of Infection}

Figure 6. Dose-response effect of phage $\varnothing 9882$ in rescuing mice from lethal ESBL-producing E. coli 9853 bacteremia. After injection of $3 \times 10^{7}$ E. coli 9853 cells, Ø9882 was injected into the mouse peritoneal cavity at various MOIs, and the fate of the mouse was observed. Mice injected with only LB broth, which was used to prepare the phage suspensions, served as control mice and are represented by circles at an MOI of 0 . There is a statistically significant difference in survival rates between mice treated with $\varnothing 9882$ at an $\mathrm{MOI} \geq 0.0001\left(10^{-4}\right)$ and untreated control mice $(\mathrm{P}<0.001)$.

Mouse model of ESBL-producing E. coli 9853-induced disease. The dose of ESBL-producing $E$. coli lethal to mice was determined by injecting mice with varying numbers of ESBLproducing E coli 9853 , ranging from $1 \times 10^{7}$ to $1 \times 10^{8} \mathrm{CFU} / \mathrm{ml}$ (Fig. 4). Intraperitoneal (i.p.) injections of $1 \times 10^{7}-2 \times 10^{7} \mathrm{CFU} / \mathrm{ml}$ ESBL-producing E. coli 9853 did not reduce the survival rate of mice during the subsequent 7-day observation period. In contrast, injections of $3 \times 10^{7}-1 \times 10^{8} \mathrm{CFU} / \mathrm{ml}$ reduced the survival rate in a dose-dependent manner. Because the injection of $3 \times 10^{7}$ ESBL-producing E. coli 9853 cells was fatal in $100 \%$ of mice within $24 \mathrm{~h}$, this level of challenge was considered to be optimal for observing the phage effect on bacterial lethality (see below). Therefore, the dose of ESBLproducing $E$. coli at $3 \times 10^{7} \mathrm{CFU} / \mathrm{ml}$ was chosen from the results mentioned above. A more precise time-chase analysis showed that i.p. injection of $3 \times 10^{7} \mathrm{CFU} / \mathrm{ml}$ ESBL-producing E. coli 9853 cells killed most mice within 8 to $14 \mathrm{~h}$ after injection, with the associated preceding bacteremia (Fig. 5 and below). The dissection of mice that died from bacterial infection $6 \mathrm{~h}$ after injection revealed severe systemic congestion with splenomegaly and acute ascites (data not shown). As seen in Fig. 5, all mice i.p. inoculated with the $\operatorname{MLD}\left(3 \times 10^{7} \mathrm{CFU} / \mathrm{ml}\right)$ of the clinical isolate ESBL-producing E. coli 9853 died within $14 \mathrm{~h}$.

Ability of the phage preparation to rescue mice from bacteremia. The phage preparations were purified by cesium chloride density centrifugation mentioned above. A single dose of phage $\varnothing 9882$ was administered immediately after the challenge with the MLD of ESBL-producing E. coli 9853. By $24 \mathrm{~h}$, a dose-response effect on the state of health of the infected animals was clearly visible. At higher phage doses, which achieved multiplicities of infection of $10^{-4}$ to 200 , $100 \%$ of the animals survived, and only minimal signs of illness (mild lethargy) were seen in the first $24 \mathrm{~h}$. As the 

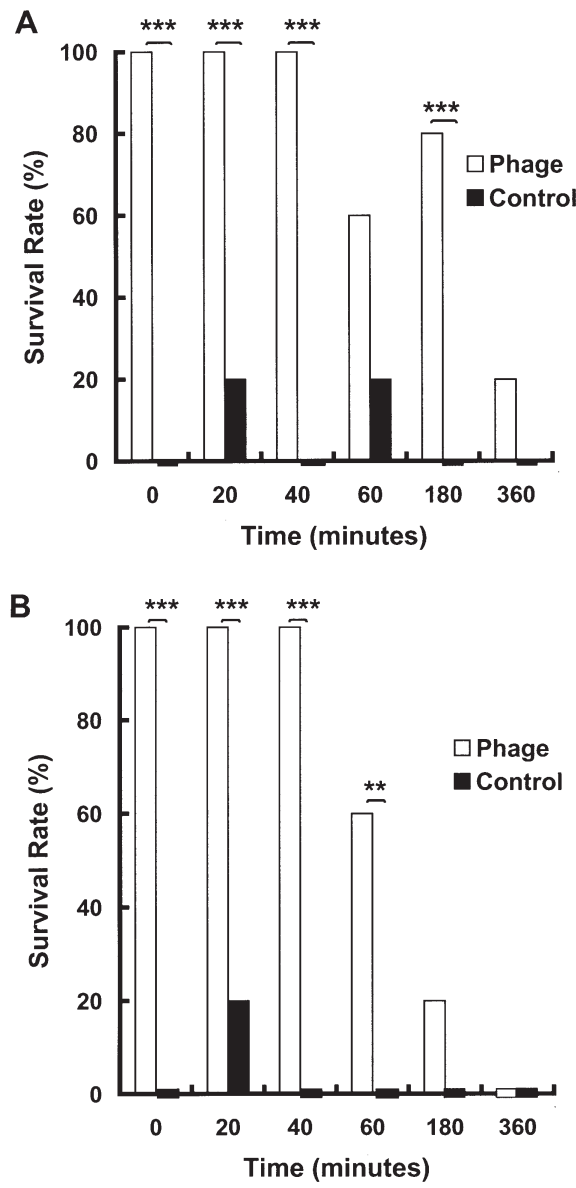

Figure 7. Protective effects with delayed administration of phage $\varnothing 9882$. Purified $\varnothing 9882$ (MOI, 200) was administered to 5 mice at the indicated time intervals, after challenge with ESBL-producing E. coli 9853 ( $3 \times 10^{7}$ cells). As a control, $0.5 \mathrm{ml}$ of phage-free $\mathrm{LB}$ was injected into mice. Survival rates were determined after 1 (A) and 7 (B) days. White and black columns represent the phage-treated and untreated mouse groups, respectively. Asterisks indicate statistically significant differences compared with that of the controls: ${ }^{* *} \mathrm{P}<0.01$ and ${ }^{* * * *} \mathrm{P}<0.001$

phage dose decreased, resulting in lower multiplicities of infection $\left(10^{-7}\right.$ to $\left.10^{-6}\right)$, the animals became critically ill, with survival rates of $0 \%$ and $20 \%$, respectively, at day 7 and beyond (Fig. 6). All of the mice that were alive and healthy at day 7 remained this way for an additional 30 days, at which point the experiment was terminated.

Effect of delay in treatment on the ability of the phage to rescue mice from bacteremia. Purified $\varnothing 9882$ was i.p. administered to mice at different times (up to $360 \mathrm{~min}$ ) after the ESBL-producing E. coli 9853 injection (Fig. 7). Although $\varnothing 9882$ administration proved to be effective at MOIs ranging widely from 0.0001 to 200 (Fig. 6), the highest MOI of 200 was applied, and subsequent investigations were conducted (see below) under the assumption that patients were in an extreme state of systemic ESBL-producing E. coli infection such as sepsis. All mice survived when treatment was delayed 40 min, and approximately $60 \%$ of mice survived even when the treatment was delayed for $1 \mathrm{~h}$. When treatment was delayed $360 \mathrm{~min}$, most of the mice treated with phage $\varnothing 9882$ were dead. The therapeutic efficacy of $\varnothing 9882$ was even discernible in mice treated 60 min after injection with bacteria, when all control mice injected with E. coli 9853 already

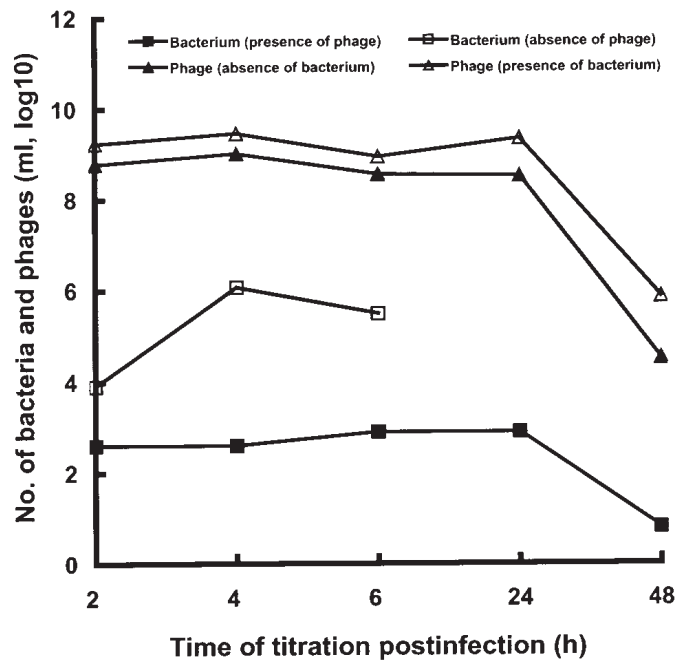

Figure 8. Rapid appearance of phage $\varnothing 9882$ in circulation. Target bacteria $\left(3 \times 10^{7}\right.$ cells) and/or $\varnothing 9882$ (MOI, 200) were i.p. injected into 3 groups of mice, each consisting of 5 mice. ESBL-producing E. coli 9853 was used as the target in this experiment. A peripheral blood sample was taken from 1 mouse of each group at 2, 4, 6, 24 and $48 \mathrm{~h}$ after injection and titrated to estimate the numbers of phages and bacteria in circulation. Black and white triangles represent plaque-forming units of $\varnothing 9882$ in the presence and absence of ESBL-producing E. coli 9853, respectively. Black and white squares represent colony-forming units of the host bacteria with and without phage administration, respectively. All mice injected with only ESBL-producing E. coli 9853 died during the observation period within $6 \mathrm{~h}$ of injection.

exhibited signs of physical deterioration, such as reduced activity and ruffled hair. Although a few Ø9882-treated mice died in the following 6 days, the survival rates among mice treated with the phage at any time point were significantly higher than those of the untreated controls (Fig. 7).

Distribution of phage $\varnothing 9882$ and E. coli 9853 in vivo. On the basis of the above results, the in vivo dynamics of the bacteria and phages were investigated in detail using ESBL-producing E. coli 9853 as the target cell. Mice were i.p. injected with $3 \times 10^{7} \mathrm{CFU} / \mathrm{ml}$ E. coli 9853 alone, E. coli 9853 plus $\varnothing 9882$ $\left(6 \times 10^{9} \mathrm{PFU} / \mathrm{ml}\right)$, or $\varnothing 9882$ alone, respectively. Bacteremia occurred within $2 \mathrm{~h}$ and persisted in the E. coli 9853 -injected mice, regardless of phage treatment (Fig. 8). However, bacterial loads in the blood were significantly lower in Ø9882-treated mice than in untreated mice in our observations (Fig. 8). Compatible with the results shown in Fig. 8, all mice injected with only E. coli 9853 died within 12 h, whereas Ø9882treated mice were invariably saved, concomitantly with subsiding septicemia within $24 \mathrm{~h}$. After $\varnothing 9882$ was injected into the peritoneal cavity, a significant number of infectious $\varnothing 9882$ was readily detected $2 \mathrm{~h}$ later in blood specimens from both the E. coli 9853 infected and uninfected mice with titers of $6.0 \times 10^{8}$ and $1.7 \times 10^{9} \mathrm{PFU} / \mathrm{ml}$, respectively. Under the circumstance of systemic dissemination of phage $\varnothing 9882$, the circulating $\varnothing 9882$ was sustained at a significant level until the target cells were eradicated, which must have counteracted the progression of bacteremia.

Effects of heat-inactivated phage. An experiment was performed to determine whether the phage rescue of mice with ESBL-producing E. coli bacteremia requires a functional phage or might be associated with a nonspecific immune 


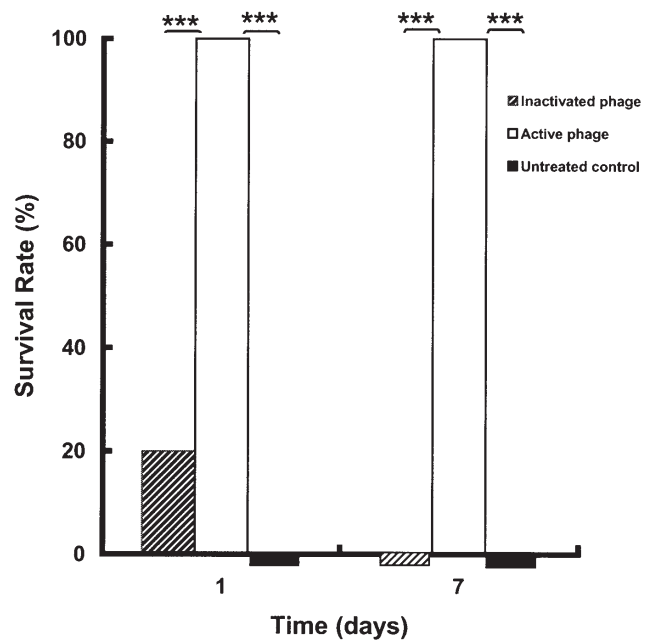

Figure 9. Comparison of the ability between active phage and nonfunctional heat-inactivated phage to rescue bacteremic mice. One group of 5 mice was treated with functional (plaque-forming) phage, while the other two groups were treated either with no phage or heat-inactivated phage. All bacteremic mice treated with functional phage survived. In contrast, only $20 \%$ of the mice in heat-inactivated groups survived at $24 \mathrm{~h}$, and all of them died within 7 days; no mice from the control group survived. A statistically significant difference $(\mathrm{P}<0.001)$ in survival rates was observed between paired groups of active phage-treated mice and heat-inactivated phage-treated or phageuntreated control mice, as signified by horizontal brackets with asterisks.

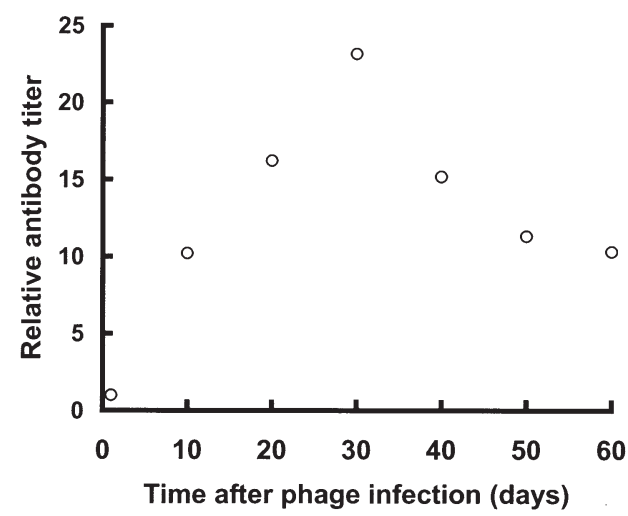

Figure 10. Antibody responses in mice to a single injection of phage $\varnothing 9882$. Phage $\varnothing 9882$ ( $10^{9}$ PFU) was i.p. injected into mice. Mouse serum was collected at varying time points following a single i.p. injection of $\varnothing 9882$, and indirect enzyme-linked immunosorbent assays (ELISAs) were performed. The titers of anti- $\varnothing 9882 \mathrm{IgG}$ were detected with goat anti-mouse IgG-specific antibody and are indicated on the plot.

activation response. Heat-inactivated phages were used to test whether a functional phage and not a nonspecific immune response is responsible for the rescue of mice inoculated with a lethal dose of ESBL-producing E. coli 9853 . Heating at $80^{\circ} \mathrm{C}$ for $2 \mathrm{~min}$ decreased the phage titer by 100 -fold, and no viable phage was detected after heating at $100^{\circ} \mathrm{C}$ for $30 \mathrm{~min}$. As illustrated in Fig. 9, only mice inoculated with plaque-forming phage had enhanced survival, with $100 \%$ survival at 7 days. By contrast, none of the PBS control mice and $0 \%$ of the mice injected with heat-inactivated phage survived.

Immune response to phage $\varnothing 9882$. After a single injection of phage $\varnothing 9882$, titers of IgG raised against the phage increased 23-fold above background (Fig. 10). IgG levels did not change substantially after 30 days. No anaphylactic reactions, changes in core body temperature, or other adverse events were observed in the mice injected with the phage.

\section{Discussion}

Pathogenic bacteria that are resistant to most, if not all, available antibiotics are responsible for increasingly serious problems in clinical settings, raising widespread fears of returning to a 'pre-antibiotic' era of untreatable infections and epidemics. As evidence, the prevalence of organisms producing ESBLs has been increasing worldwide. ESBLproducing $E$. coli is broadly resistant to third-generation cephalosporins. Based on the current experience, imipenem (Carbapenems) appears to be the best alternative choice for the treatment of severe infections caused by ESBL-producing E. coli (31). However, with the excessive and widespread use of imipenem, there exists the possibility of an emergence of resistant organisms to antibiotics in the near future. Confronted with the dilemma in the clinic, it is necessary to explore the potential therapeutic applications of phages. Matsuzaki et al (32) and Biswas et al (29) used phages to treat experimental MRSA and VRE infections in mice, respectively, and both achieved encouraging results, showing that phages are effective in treating bacterial infections in animal models and provide a reliable alternative therapeutic approach. These studies reported some important insights into the potential of phage therapy against various bacterial infectious diseases.

In the current study, we demonstrated that phage $\varnothing 9882$, with its broad host range, is highly active and rapidly lytic in vitro, and effective in preventing and treating ESBLproducing $E$. coli infection in mice. Our data revealed that i.p. inoculation of $\varnothing 9882$ given $40 \mathrm{~min}$ after the bacterial challenge led to $100 \%$ survival at $24-168 \mathrm{~h}$, compared to $0 \%$ survival of saline-treated controls. Protection was also obtained when phage administration was delayed up to $60 \mathrm{~min}$ after the bacterial infection, and the survival rate of infected animals was $60 \%$ at $168 \mathrm{~h}$. Even if treatment was delayed up to $3 \mathrm{~h}$, approximately $20 \%$ of animals were rescued and recovered completely, suggesting that acute infections may be amenable to phage treatment. Matsuzaki et al (32) and Soothill (27) independently reported that a MOI of 1 was the minimum used in their studies to produce a fully protective effect in a mouse model. In contrast, our experiments showed that the mimimum MOI is $0.0001\left(10^{-4}\right)$. The result demonstrates that phage $\varnothing 9882$ possesses an astonishing bacteriolytic ability. An antibiotic therapeutic effect in infected mice requires an appropriate dosing interval of administration to maintain pharmacological concentrations in serum. Of interest, a single i.p. injection of a lytic phage(s) was sufficient for the complete clearance of invading $E$. coli from surviving mice. This property, referred to as therapeutic efficacy, provides a rapid and specific lytic activity, thus making these phages very promising candidates in current antimicrobial therapies.

Our study also showed that phage $\varnothing 9882$ can rapidly enter circulation, accumulate in the tissues and blood to a sufficiently high concentration to be practically useful, and even cross the blood-brain barrier according to some reports (33), which implies a rapid systemic distribution of the phage 
in vivo. Matsuzaki et al (32) and Merril et al (34) found that phage particles can be detected from different tissues and/or organs, such as the spleen, liver, kidney, brain and skeletal muscle. Our data also indicate that infectious $\varnothing 9882$ was maintained at relatively higher levels in the bloodstream. $\varnothing 9882\left(6 \times 10^{9} \mathrm{PFU} / \mathrm{ml}\right)$ retained a high titer of $1.7 \times 10^{9} \mathrm{PFU} / \mathrm{ml}$ in bloodstream $24 \mathrm{~h}$ after i.p. injection, and was as high as $\sim 10^{6} \mathrm{PFU} / \mathrm{ml}$ until $48 \mathrm{~h}$ after injection. The levels of phage in the circulation are correlated with its antibacterial efficacy and therapeutic effectiveness. It was reported that phages persisted without a reduction in particle numbers on the skin for at least $48 \mathrm{~h}$. Others showed that phages persisted long enough in the tissues to be effective when administered to chickens 1-2 days before the challenge with E. coli. Our data and those of others support the view that phage dosages can be used regardless of its rejection by the body, suggesting the possibility of prophylaxis $(29,35,36)$.

Furthermore, our experiments demonstrate that ability of the phage to rescue bacteremic animals was the phage function and not a nonspecific immune activation response, although phage $\varnothing 9882$ caused an immune response in mice, and IgG antibodies reached a maximum over the course of 20-30 days after a single phage injection. Our data both in vitro and in vivo revealed that: i) the protection of mice from death occurred only in animals infected with selected bacterial strains and the virulent phage specific to them; ii) when the phages were heat-inactivated, the survival of the infected mice was strikingly decreased to 0 ; and iii) the level of antibody against the phage was not significantly changed when the bacteremic animals were protected by the active phages. These results are consistent to those of Biswas et al (29). Additionally, Matsuzaki and co-workers confirmed that a 'mechanical' lysate of $S$. aureus did not induce an antibacterial effect, and phages had no therapeutic effect against infections with phage-lysogenic host bacteria (32). Lastly, bacterial antigens, such as endo- and exotoxins, must have been removed by repeated cesium chloride density centrifugation purification from the $\varnothing 9882$ preparations (28), which are less prone to induce an immune response and cause side effects, as evidenced by the lack of any adverse effects in the control group mice inoculated with a high dose of the phage preparation.

Our results indicate that phages have the potential to prevent and/or treat certain bacterial infections in animals and, by extension, in humans. It is tempting to advocate investigation into several bacterial infections for which animal models are available and for which phages may be isolated. However, phage therapy as an alternative to antibiotics for bacterial infections could only become a practical measure under certain conditions and requires further study. First, most phages are highly host-specific and showed a close and narrow host range. A phage targets specific bacteria, usually a specific bacterial strain, and ignores other bacteria. Using a cocktail of lytic phages should minimize the risk of bacteria resistance to phage therapy. Second, phage biochemistry and gene characteristics were immature, resulting in the preparation of phage of variable quality, either contaminated with bacteria or their components. Sophisticated purification technology, such as purification of cesium chloride density centrifugation, can avoid the complications of earlier therapies. Finally, applying this strategy successfully will be technically difficult.
The parenteral inoculation of phage could be used for mass treatment, but oral administration would be more convenient, and although there have been reports on the translocation of phages administered orally across the gut (37), it would seem unlikely that phages could accumulate in the tissues and blood to a sufficiently high concentration to be practically useful.

The present study reinforces the view that the potential of phage therapy is worth exploring. It is anticipated that bacteriophage therapy will be a powerful weapon against antibioticresistant bacteria and could provide a novel approach to the treatment of systemic bacterial infections. Given the increasing problems of bacterial disease and bacterial antibiotic resistance worldwide, it would appear timely to begin a search for lytic phages with potential therapeutic strength and evaluate the therapeutic effectiveness of phage treatment for systemic lethal ESBL-producing bacteria infections in humans.

\section{Acknowledgements}

This publication was made possible by the Cheng-Guang Projects for Young Scientists from the Department of Science and Technology of Wuhan, China (no. 20025001026 to J. Hu), and a grant from the National Institutes of Health, Bethesda, MD, USA (no. P20RR16440-010003 to Q.Q. Li).

\section{References}

1. Knothe H, Shah $\mathrm{P}$ and Antal M: Transferable resistance to cefotaxime, cefoxitin, cefamandole, and cefuroxime in clinic isolates Klebsiella pneumoniae and Serratia marcescens. Infection 6: 315-317, 1983 .

2. Fierer J and Guiney D: Extended-spectrum ß-lactamases: a plague of plasmids. JAMA 281: 563-564, 1999.

3. Lan QX, Liu HC and Fang M: Analysis of antimicrobial resistance of clinical isolates of Escherichia coli. Proc Sichuan University Med Edition 36: 90-92, 2005.

4. Samaha-Kfoury A: Recent developments in B-lactamases and extended spectrum ß-lactamases. Br Med J 327: 1209-1213, 2003.

5. Bradford PA: Extended spectrum B-lactamases in the 21st century, characterization, epidemiology, and detection of this important resistance threat. Clin Microbiol Rev 14: 933-951, 2001.

6. Philippon A, Arlet G and Lagrange PH: Origin and impact of plasmid mediated extended spectrum B-lactamases. Eur J Clin Microbiol Infect Dis 13: 17-29, 1994.

7. Lee NLS, Yuen KY and Kumana CR: ß-lactam antibiotic and B-lactamase inhibitor combinations. JAMA 285: 386-388, 2001.

8. Ahmed I and Salam A: Extended spectrum ß-lactamases and bacterial resistance. Pak J Med Sci 18: 151-155, 2002.

9. Ling TKW, Liu EYM and Cheng AFB: A 13-year study of antimicrobial susceptibility of common Gram-negative bacteria isolated from the bloodstream in a teaching hospital. Chemotherapy 47: 29-38, 2001.

10. Huang X, Xu XH, Wen XM, Huang X, Li J and Wu AH: Antimicrobial resistance of Gram-negative bacilli isolated from patients in intensive care unit. Zhongguo Wei Zhong Bing Ji Jiu Yi Xue 17: 409-411, 2005.

11. Kader AA and Kumar A: Prevalence and antimicrobial susceptibility of extended spectrum B-lactamase producing Escherichia coli and Klebsiella pneumoniae in a general hospital. Ann Saudi Med 25: 239-242, 2005.

12. Cohen ML: Epidemiology of drug resistance: implications for a post antimicrobial era. Science 257: 1050-1055, 1992.

13. Clark NM, Hershberger E, Zervosc MJ and Lynch JP: Antimicrobial resistance among gram-positive organisms in the intensive care unit. Infect Dis 9: 403-412, 2003.

14. Thacker PD: Set a microbe to kill a microbe: drug resistance renews interest in phage therapy. JAMA 290: 3183-3185, 2003.

15. Kutter E: Phage therapy. In: Bacteriophages as Antibiotics. Evergreen State College, Olympia, Washington, 1997.

16. Sulakvelidze A, Alavidze Z and Morris JG: Bacteriophage therapy. Antimicrob Agents Chemother 45: 649-659, 2001. 
17. Stone R: Stalin's forgotten cure. News focus. Science 298: 728-731, 2002.

18. Ho K: Bacteriophage therapy for bacterial infections. Perspect Biol Med 44: 1-16, 2001.

19. Alisky J, Iczkowski K, Rapoport A and Troitsky N: Bacteriophages show promise as antimicrobial agents. J Infect 36: 5-15, 1998.

20. Slopek S, Weber-Dabrowska B, Dabrowski M and KucharewiczKrukowska A: Results of bacteriophage treatment of suppurative bacterial infections in the years 1981-1986. Arch Immunol Ther Exp 35: 569-583, 1987.

21. Weber-Dabrowska B, Mulczyk M and Górski A: Bacteriophage therapy of bacterial infections: an update of our institute's experience. Arch Immunol Ther Exp 48: 547-551, 2000.

22. Travis J: Viruses that slay bacteria draw new interest. Science News 157: 358-359, 2000.

23. Smith HW and Huggins MB: Successful treatment of experimental Escherichia coli infections in mice using phage: its general superiority over antibiotics. J Gen Microbiol 128: 307-318, 1982.

24. Smith HW and Huggins MB: Effectiveness of phages in treating experimental Escherichia coli diarrhoea in calves, piglets, and lambs. J Gen Microbiol 129: 2659-2675, 1983.

25. Smith HW, Huggins MB and Shaw KM: Factors influencing the survival and multiplication of bacteriophages in calves and in their environment. J Gen Microbiol 133: 1127-1135, 1987.

26. Smith HW, Huggins MB and Shaw KM: The control of experimental Escherichia coli diarrhoea in calves by means of bacteriophages. J Gen Microbiol 133: 1111-1126, 1987.

27. Soothill JS: Treatment of experimental infections of mice with bacteriophages. J Med Microbiol 37: 258-261, 1992.
28. Sambrook J, Fritsch EF and Maniatis T: Molecular cloning: A laboratory manual. 2nd edition. Vol. 1. Cold Spring Harbor Laboratory Press, Cold Spring Harbor, NY, pp66-79, 1989.

29. Biswas B, Adhya S, Washart P, Paul B, Trostel AN, Powell B, Carlton R and Merrill CR: Bacteriophage therapy rescues mice bacteremic from a clinical isolate of Vancomycin-resistant Enterococcus faecium. Infect Immun 70: 204-210, 2002.

30. Adams KH: Bacteriophages. Wiley-Interscience, New York, 1959.

31. Dolapci I: Extended-spectrum ß-lactamases: their role in clinical microbiology laboratory, treatment and infection control. Mikrobiol Bul 39: 229-240, 2005.

32. Matsuzaki S, Yasuda M, Nishikawa H, Kuroda M, Ujihara T, Shuin T, Shen Y, Jin Z, Fujimoto S, Nasimuzzaman MD, Wakiguchi H, Sugihara S, Sugiura T, Koda S and Muraoka A: Experimental protection of mice against lethal Staphylococcus aureus infection by novel bacteriophage ØMR11. J Infect Dis 187: 613-624, 2003.

33. Barrow P, Lovell $\mathrm{M}$ and Berchieri A: Use of lytic bacteriophage for control of experimental Escherichia coli septicemia and meningitis in chickens and calves. Clin Diagn Lab Immunol 5: 294-298, 1998.

34. Merril CR, Biswas B, Carlton R, Jensen NC, Creed GJ, Zullo S and Adhya S: Long-circulating bacteriophage as antibacterial agents. Proc Natl Acad Sci USA 93: 3188-3192, 1996.

35. Dean JH, Silva JS and McCoy JL: In vitro human reactivity to staphylococcal phage lysate. J Immunol 115: 1060-1064, 1975.

36. Carlton RM: Phage therapy: past history and future prospects. Arch Immunol Ther Exp 47: 267-274, 1999.

37. Hildebrand GJ and Wolochow H: Translocation of bacteriophage across the intestinal wall of the rat. Proc Soc Exp Biol Med 109: 183-185, 1962. 